\title{
The conservation of basins and the irrigation districts in Mexico
}

\author{
R. Lomeli Villanueva ${ }^{1} \&$ N. Alvarez Gonzalez ${ }^{2}$ \\ ${ }^{1}$ Instituto Mexicano de Tecnologia del Agua, Mexico \\ ${ }^{2}$ Comision Nacional del Agua, Mexico
}

\begin{abstract}
In Mexico, large irrigation districts were constructed with dams on the mainstream as sources of supply to store the rainwater and then distribute the stored volumes for agricultural purposes. Irrigated farming generates more than half of the national agricultural production. One of the main problems of the infrastructure maintenance is the accumulation of sediments in the distribution and drainage networks, caused fundamentally by insufficient actions of soils and water conservation in the basins of the irrigation dams. The present work analyzes the impact of the catchment basins degradation in the accumulation of sediments in the irrigation districts.

Keywords: sediment removal, irrigation district maintenance, catchment basins, soil and water conservation works.
\end{abstract}

\section{Introduction}

In Mexico, the area dedicated to agricultural activity varies between 21 and 24 million hectares annually. The surface with infrastructure for irrigation is 6.4 million hectares, Mexico ranks sixth place in the world, in terms of irrigation areas made of 86 irrigation districts with 3.5 million hectares and 39,482 irrigation units of small irrigation with 2.9 million hectares [1-3].

In addition, there are areas called Temporal Tecnificado districts which directly depend on rainfall, with no irrigation infrastructure, but using different techniques and work to reduce the damage caused by the occurrence of heavy and prolonged rains or drought, to improve the gathering of rain and moisture in farming lands. 
The agricultural production of the irrigation districts contributes directly in the development of the country because it represents one third of the national food production, and involves over half a million of irrigation users. These products represent about $60 \%$ of the value of the domestic production.

The infrastructure of irrigation districts are made up as follows [4]:

- $\quad 139$ storage dams;

- 345 diversion dams;

- $\quad 14,490$ wells;

- $\quad 345$ pumping plants;

- $\quad 7855$ miles of main canals and 22,690 miles of secondary canals, $47.3 \%$ of the canals are lined;

- $\quad 5943$ miles are collector drains and 13420 miles are secondary drains;

- 43,573 miles of roads, of which $51 \%$ are earth road, $41 \%$ with revetment and the rest are paved;

- $\quad 3468$ units of machinery and equipment for infrastructure maintenance.

The following is a summary table of the classification of canals and drains, according to their main characteristics which are the bottom and the depth of water (as shown in figure 1).

\section{Canals and drains cross section}

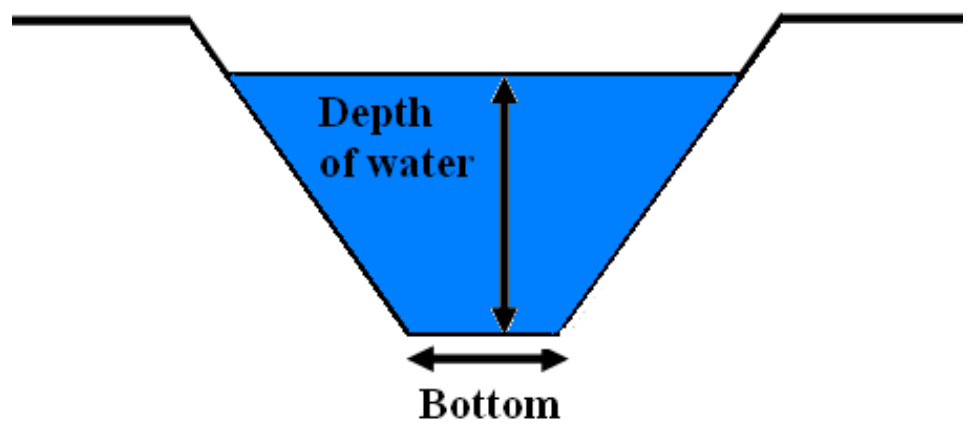

Figure 1: Cross section of canals and drains.

Table 1: Characteristics and percentages within the national territory of canals and drains.

\begin{tabular}{|l|l|l|l|l|}
\hline \multirow{2}{*}{ Type } & \multicolumn{1}{|c|}{$\begin{array}{c}\text { Bottom } \\
(\mathbf{m})\end{array}$} & \multicolumn{1}{|c|}{$\begin{array}{c}\text { Depth of water } \\
\mathbf{( m )}\end{array}$} & \multicolumn{1}{|c|}{ Canals } & Drains \\
\cline { 4 - 5 } & & & $\mathbf{( \% )}$ & $\mathbf{( \% )}$ \\
\hline E & Less than 2 & Less than 1.2 & 76.2 & 40.4 \\
D & Between 2 and 4 & Between 1.3 and 1.7 & 13.8 & 28.9 \\
C & Between 4 and 6 & Between 1.8 and 2.4 & 5.4 & 16.9 \\
B & Between 8 and 10 & Between 2.5 and 3.0 & 1.4 & 8.0 \\
A & Between 10 and 20 & More than 3.0 & 3.2 & 5.8 \\
\hline
\end{tabular}


The infrastructure maintenance is an action to be performed periodically and permanently in order to preserve its state, under conditions closer to the original project.

To maintain the infrastructure in optimal conditions it is essential to provide a good irrigation service, that is, to deliver water to crops timely and sufficient, which will get an optimum crop production.

The development of surface irrigation in Mexico is limited, and currently, there are few sources of water economically available, therefore, to maintain or improve the productivity of the irrigation district is priority for optimal maintenance of infrastructure

The maintenance of the infrastructure is basic to improve the operation of the irrigation districts and to fulfill with the irrigation schedule.

In Mexico to make a quick and economical field works, manpower, heavy weight machinery as long reach hydraulic excavator (Figure 2) and equipment as backhoe loaders are used.

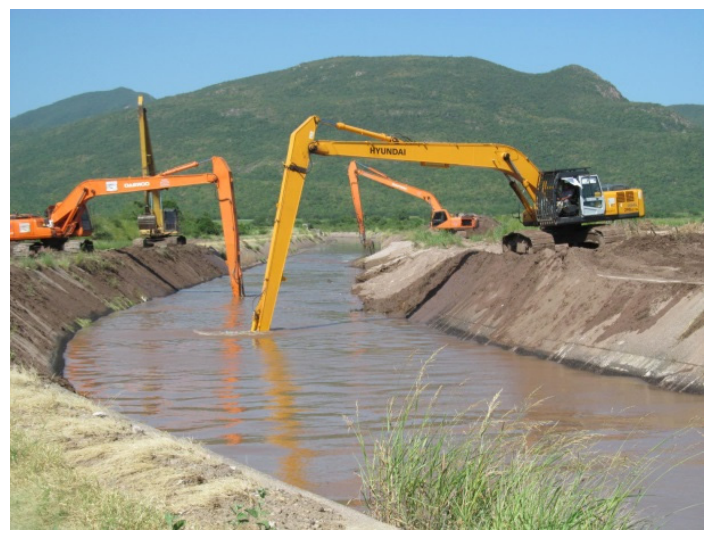

Figure 2: Long reach excavators removing sediments in an irrigation canal.

\section{Problematic}

Heavy rainfall associated with tropical cyclones, coupled with factors such as topography, land use, vegetation cover and inadequate infrastructure for the conservation of soil and water, causes runoff carrying a great quantity of suspended soil particles that are deposited in storage reservoir, reducing the life of dams and also water for irrigation this carry suspended solids not deposited in the reservoir.

These suspended solids are deposited in the form of sediments along the distribution network. Also, as a side effect, favors the development of weeds in the bottom.

In the case of the drainage network, the properties that are not irrigated efficiently carry a large amount of suspended solids; another source is the flooding due to storm water that falls to the drainage network. 
The investment in infrastructure for irrigation is high; water to one hectare of land (dam construction, infrastructure, etc.) has a cost of over $5000 €$, the infrastructure rehabilitation requires approximately $1000 €$, while the maintenance, has a cost of about $18 €$, making it extremely profitable to perform the work of preserving the infrastructure of the irrigation districts to obtain the sustainable water use matter.

The main maintenance concepts in the irrigation districts are:

- Sediments removal in canals and drains;

- Tracking, forming and coating roads replacement;

- Repair of structures and mechanisms;

- Weed Control (aquatic and terrestrial);

- Canals slabs replacement;

- Dams, wells and pumping plant preventive maintenance.

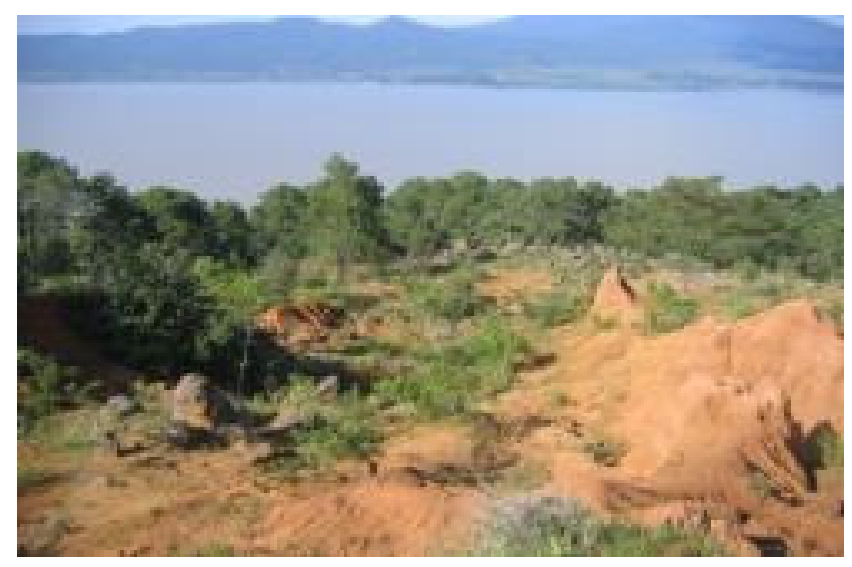

Figure 3: Degraded basin.

Annually, irrigation districts remove about 5 million cubic yards of sediment in distribution networks and 8 million in the drainage network, which means more than 13 million cubic meters per year total.

The main causes of sediment accumulation are:

- Uncontrolled water from natural channels into canals and drainage networks;

- Irrigation water with suspended solids;

- Inadequate protection of the canal slopes with grassland.

Most of the irrigation districts' sources are storage dams but as there are not enough soil and water conservation works in their basins, it causes soil erosion in the highlands. Water particles of such soil move down and deposits in the storage reservoirs, reducing the dams' usefulness and also producing the accumulation of sediments in the distribution network. These sediments also facilitate the development of weeds in the bottom. 


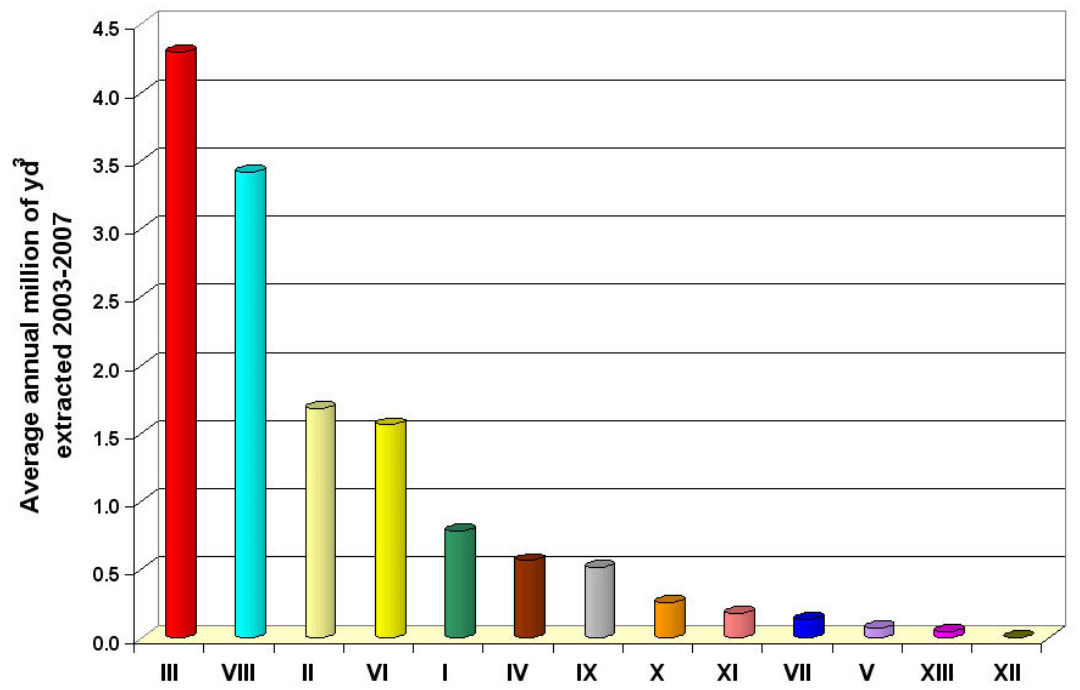

Figure 4: Average annual million of $\mathrm{yd}^{3}$ extracted distributed by the National Water Commission Basin Agency.

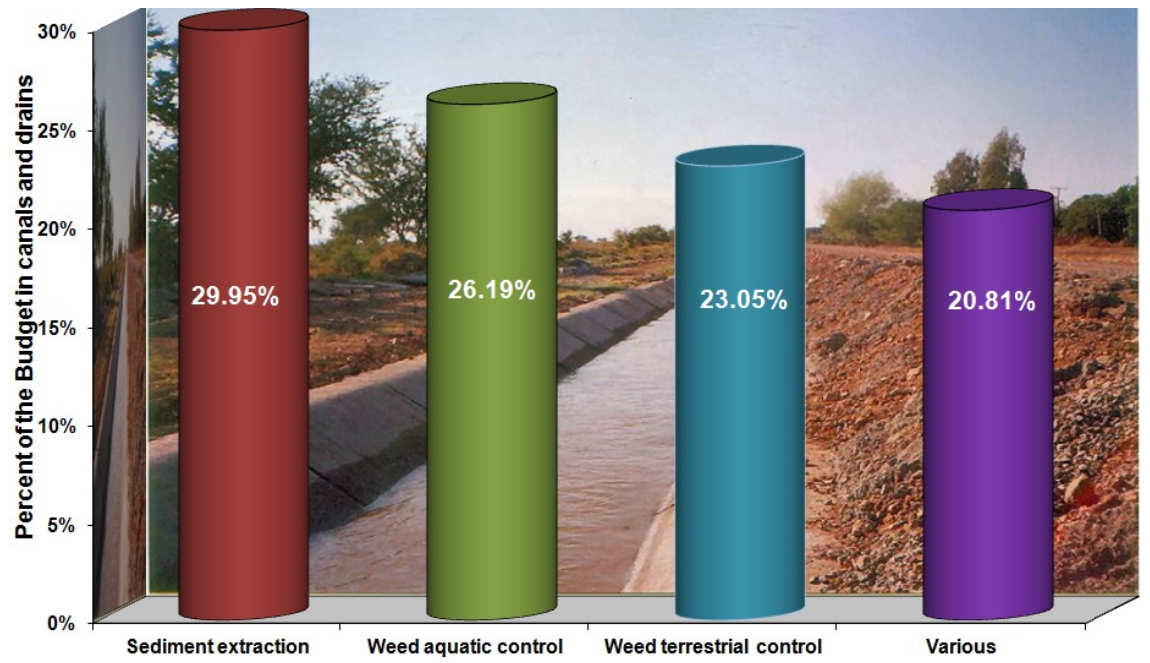

Figure 5: Distribution of the budget for maintenance works in canals and drains.

Almost $23 \%$ of the budget in the irrigation districts is used for sediment removal. The distribution of the budget for maintenance works is presented in figure 5 . 
To prevent sediments problems in the slopes of canals and drains of D and E types (Table 1), in $90 \%$ of canals and $69.3 \%$ of drains, the National Water Commission in coordination with the Mexican Institute of Water Technology, developed and transferred the technology of using lightweight equipment for weed control and allow the growing of grass to protect the slopes, and also facilitate the removal of aquatic weeds in canals and drains.

It should be noted that currently there are over 300 pieces of lightweight equipment in the irrigation districts.

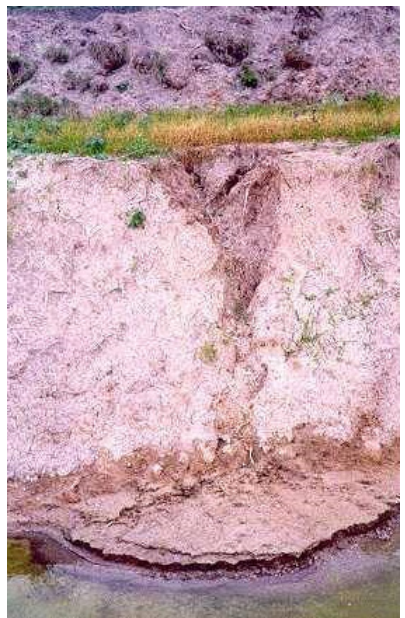

Figure 6: Unprotected slopes causes accumulation of sediments in canals.

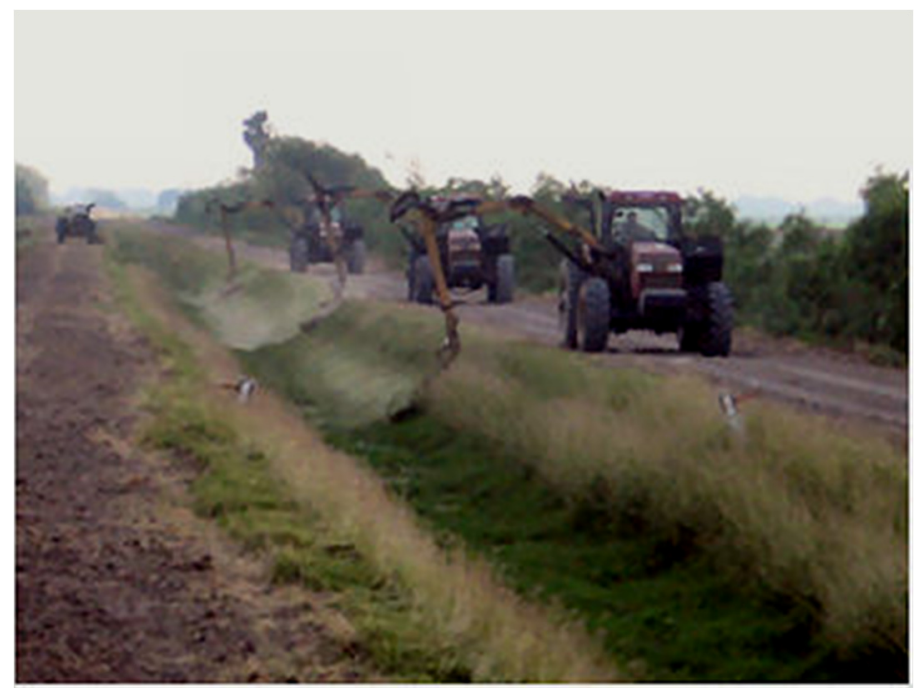

Figure 7: Lightweight equipment in an irrigation canal. 


\section{Investment in maintenance}

Under normal conditions, about the $50 \%$ of the irrigation districts' budget should be invested in maintenance programs, in order to ensure the optimal state of infrastructure in the irrigation districts.

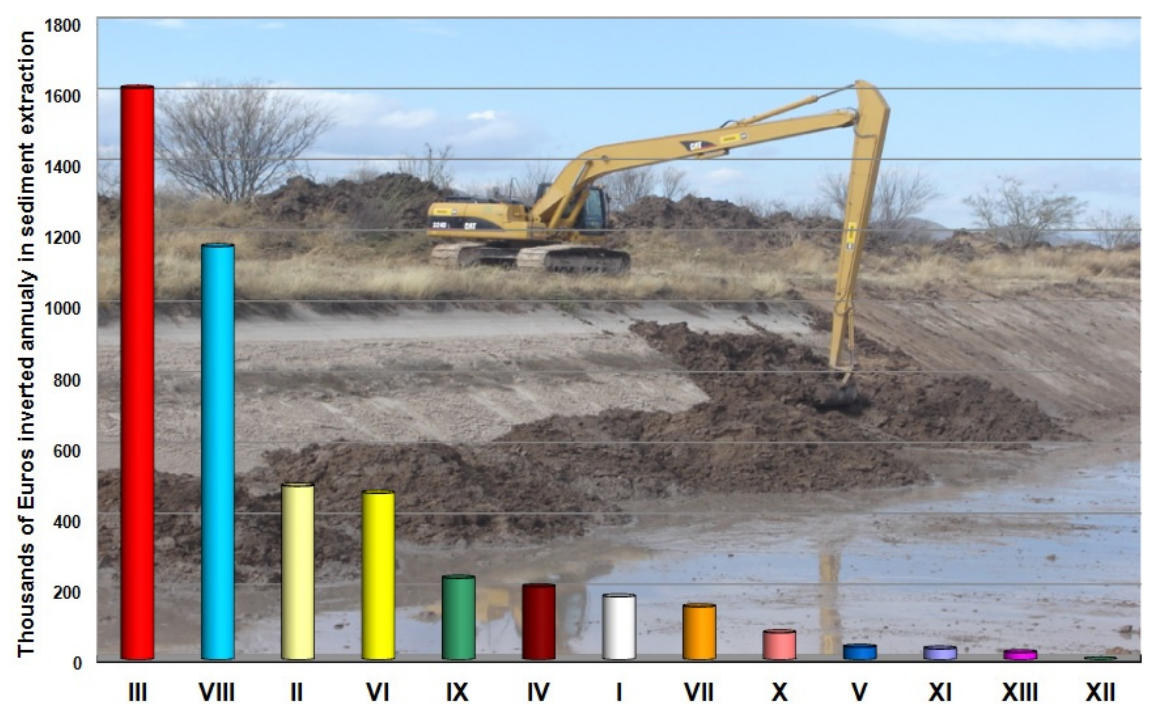

Figure 8: Average budget used in sediments extraction by the National Water Commission Agency Basin.

The Pacifico Norte National Water Commission Agency Basin invests more than $1,600,000 €$ in sediment extraction because the storage dams basins are among the largest in the country and are deteriorated. Below is the Lerma Santiago Pacífico National Water Commission Agency Basin, which is supplied with water from the Lerma River, one of the largest in the central basin of the country which is heavily damaged.

\section{Conclusions}

The lifetime of most storage dams has decreased significantly due to the sediments accumulation caused by inadequate soil and water conservation works in the catchment basins.

Irrigation districts in Mexico have upgraded their equipment and machinery to remove sediments and to protect the slopes of canals and drains at lower costs.

20 percent of the irrigation district budget is used to extract sediments. The average maintenance cost is $110 € /$ mile, in the distribution network and $157 € /$ mile in the drainage network. 


\section{Recommendations}

Enhance the works of soil and water conservation in the impounding basins of the dams of the irrigation districts.

Promote the modernization and technical activities in the irrigation districts, to increase water efficiency application in irrigation and avoid the risk of causing damage to the soil level plots.

\section{References}

[1] Water National Commission, Efficient use of water and electricity Coordination, Small irrigation units organized and unorganized. 1999

[2] Water National Commission. Irrigated areas and volumes of water distributed in the irrigation districts crop year 2011 and 2012. Edition 2013

[3] Water National Commission. Statistics of irrigation districts. 2013

[4] Water National Commission. Inventories of infrastructure, machinery and equipment of the irrigation districts. 2014 